\title{
Study of the wind drag coefficient during the storm Xaver in the German Bight using data assimilation
}

\author{
Xiangyang Zheng ${ }^{\mathrm{a}, \mathrm{c}}$, Roberto Mayerle ${ }^{\mathrm{b}}$, Yebao Wang ${ }^{\mathrm{c}}$, Hua Zhang ${ }^{\mathrm{c}, *}$ \\ ${ }^{\mathrm{a}}$ Institute of Oceanology, Chinese Academy of Sciences, Qingdao, 266071, China \\ ${ }^{\mathbf{b}}$ Research and Technology Center, Westcoast, University of Kiel, Kiel, Germany \\ ${ }^{\mathrm{c}}$ Key Laboratory of Coastal Environmental Processes and Ecological Remediation, Yantai Institute of Coastal Zone Research, Chinese Academy of \\ Sciences, Yantai 264003, China
}

\section{A R T I C L E I N F O}

\section{Keywords:}

German Bight

Wind drag coefficient

4Dvar

Storm surge modeling

\begin{abstract}
A B S T R A C T
Wind stress is the most important driving force for storm surge in coastal waters. Currently, the parameterization of wind stress is still not well developed and is the most uncertain parameters for storm surge models. In this paper, a storm surge model for the German Bight is developed using the model Delft3D. The data assimilation method, adjoint-free 4Dvar, which is relatively easier to be implemented than the adjoint method, is used to assimilate measured water level data into Delft3D. The storm surge prediction is more accurate when we adjusted the drag coefficient using the adjoint free data assimilation method, than in a companion forward model. The drag coefficient is consistent with results from previous studies. The wind drag coefficient is also calculated using results of a wave model. It has been found that the relation between the drag coefficient and wind speed is approximately linear in the deep water. But in the shallow water, wind drag coefficient shows larger variability due to the wave shoaling effect. The linear relation adjusted by data assimilation agrees well with that derived from a wave-related formula. It is also found that wave-related parameterization scheme is necessary for shallow waters.
\end{abstract}

\section{Introduction}

Wind stress $\tau$ is parameterized as a function of air density $\rho_{\text {air }}$, wind drag coefficient $C_{d}$ and wind speed $U, \tau=\rho_{\text {air }} C_{d} U|U|$. It accounts for the air-sea momentum transfer and is one of the main driving forces of ocean dynamics. Dietrich et al. (2018) studied the sensitivity of storm surge prediction to hurricane data from different sources during Hurricane Isaac (2012); they found that wind field generated by a fully coupled atmosphere-wave-ocean model improves surge prediction compared with wind field from an analysis product and a parametric model. The method of calculating wind drag coefficient $C_{d}$ over the sea surface is still under investigation. Variation of $C_{d}$ on the sea surface is more complex with comparison to that on land because the sea surface roughness changes with wave state. Over the last decades, many researchers (Smith and Banke, 1975; Large and Pond, 1981) have studied on the variations of $C_{d}$ using data from field measurements or laboratory work. They have found that $C_{d}$ is approximately a linear function of wind speed under intermediate or high wind speed, that is,

$$
C_{d}=10^{-3}\left(a+\mathrm{bU}_{10}\right)
$$

where $U_{10}$ is wind speed $10 \mathrm{~m}$ above sea surface, $a$ and $b$ are parameters to be determined by observation data. A number of linear functions are derived from different researchers (Wu, 1969; Geernaert et al., 1987; Yelland and Taylor, 1996), indicating the function

\footnotetext{
* Corresponding author:

E-mail address: hzhang@yic.ac.cn (H. Zhang).
} 
for wind drag coefficient contain large uncertainty. However, the linear function is still widely used (Feng et al., 2016; Krien et al., 2017; Wang et al., 2017a) because it can be easily implemented into an ocean hydrodynamic model. Storm surge is induced by strong wind and poses a severe threat to coastal areas. The forecast skill of storm surge relies heavily on the parametrization of wind stress. Under stormy weather conditions, wind stress plays much greater roles in the water level variations than under normal weather conditions. Weaver and Slinn (2015) implemented seven existing functions of $C_{d}$ into the storm surge model ADCIRC and found that the model results vary significantly and are quite sensitive to $C_{d}$, indicating that the wind drag coefficient is the main limiting factor for the storm surge model skill.

Many efforts have been taken to improve the parameterization of $C_{d}$ by using more nonlinear functions (Amorocho and DeVries, 1980), more parameters (Gao et al., 2009) or GPS sonde data (Powell et al., 2003). Apart from direct observations of wind stress, researchers also used data assimilation, numerical models and observations to adjust the linear function of $C_{d}$ and improve storm surge model skill. In parameter estimation, parameters are adjusted statistically in an iterative optimization problem to reduce a global model data misfit function, bringing the model closer to the observations (Lahoz et al., 2010), However, whether the model parameters are reasonably adjusted or not are not fully discussed in the literature. Broquet et al. (2011) found that abnormal spatial and temporal variability in the structure of the wind stress is generated when the wind stress is corrected by data assimilation. Peng et al. (2013) performed a series of twin experiments on a storm surge model. He found that data assimilation is able to improve the model skill of surge forecasting. He also mentioned that data assimilation can also reduce model errors caused by inaccurate wind speed data and other errors sources, such as insufficient model grid resolution. Li et al. (2013) found that adjusting initial conditions only may introduce unrealistic oscillations out of the assimilation window, which can be suppressed by adjusting wind stress.

In this paper, we will show how data assimilation improves storm surge simulation skill by adjusting the linear function of wind drag coefficient $C_{d}$. Apart from linear function of $C_{d}$ with respect to wind speed, $C_{d}$ derived from other methods are also considered. Wave-related wind drag coefficient $C_{d}$ is regarded to be more consistent with what happens over the sea surface in nature. The linear function $C_{d}$ is mainly compared with wave-related $C_{d}$ to discuss the physical validity of the linear function and whether data assimilation is not only able to improve model skill but also adjust the linear function of wind stress in a way consistent with wind-wave coupling process.

The paper consists of five sections. In the second section, the numerical models for storm surge and wave are introduced, as well as the data assimilation method and how the wave state influences the wind drag coefficient. In the third section, the improvement of the storm surge model are presented. In the fourth section, the wind drag coefficient adjusted by data assimilation and calculated from the wave-wind process is discussed in more details. Finally, the conclusions of this paper are given.

\section{Data and method}

\subsection{Model}

The hydrodynamic model used in this study is Delft3D FLOW. Delft3D FLOW is a three dimensional (3-D), free surface hydrodynamic model for continental shelf, coastal, estuarine waters. It solves the large scale Navier-Stokes equations for incompressible fluid on a orthogonal curvilinear grid. The model simulates phenomena driven by tidal and meteorological forcing. Sigma coordinate is used for vertical grid in 3-D simulations. Delft3D FLOW is widely used in the coastal hydrodynamic research (Jiao, 2014; Kuang et al., 2016; Wang et al., 2017b). The wave model for the study is the module WAVE of Delft3D. The wave model of WAVE module is SWAN, a third generation wave model, which simulates random, short-crested wind-generated waves in coastal regions and inland waters. SWAN computes two-dimensional wave action density spectrum on a curvilinear grid. In Delft3D, the module FLOW and WAVE have a coupling process on the bottom friction and radiation stress, but there is no coupling on the sea surface stress. For more details about the FLOW and WAVE module of Delft3D, readers are referred to the manuals of FLOW (Hydraulics, 2007) and WAVE (Hydraulics, 2002).

The study area is German Bight (Fig. 1), which is in the southeast of the North Sea. Due to the coastline geometry, German Bight is one of the most vulnerable areas to storm surge in Europe. The maximum water depth of German Bight is about $50 \mathrm{~m}$ in the northwest. There is a shelf break in the middle part of German Bight, where water depth decreases sharply from $40 \mathrm{~m}$ to $30 \mathrm{~m}$. Between the shelf break and the coastal islands, the depth is about $15-30 \mathrm{~m}$ in most area. In order to have a complete wind effect on the water level variation, a nesting model system is adopted as shown in Fig. 2. The larger model covers the whole Northwest European continental shelf (CSM) with about $9 \mathrm{~km}$ horizontal resolution of the grid. The smaller model covers the German Bight (GBM). The open boundary conditions of the larger model are water level data reproduced by tidal harmonic constants from a global ocean tides model TPXO (Egbert and Erofeeva, 2002). The GBM model is nested on the CSM model, obtaining water level along the open boundary from the CSM model. The bathymetry data are from multi-year surveys. The wind $10 \mathrm{~m}$ above the sea surface and air pressure data used in the storm surge model are from a global meteorological model operated by German Weather Certer (DWD) with spatial resolution of $7 \mathrm{~km}$ and time interval $1 \mathrm{~h}$ (COSMO, 2007). The modeled wind field is validated by comparing it with observations of wind speed at three stations in the German Bight. The three stations are Sylt, Helgoland and Norderney as shown in Fig. 2. Scatter plots in Fig. 3 indicate that the simulated wind at the three stations agrees well with observations. The correlation coefficient between them is as high as 0.93 and 0.95 for east and north component respectively. The root mean square deviations (RMSDs) between them are relatively small. Therefore, it is assumed that storm surge model errors caused by the inaccuracy are sufficiently small. The grids of the wave model are the same as the storm surge model. In Delft3D FLOW, The linear function (Eq. (1)) of wind drag coefficient $C_{d}$ relative to wind speed $10 \mathrm{~m}$ above the sea surface is used.

The storm surge caused by the storm Xaver in the winter of 2013 is investigated as a study case. The storm Xaver originated off the 


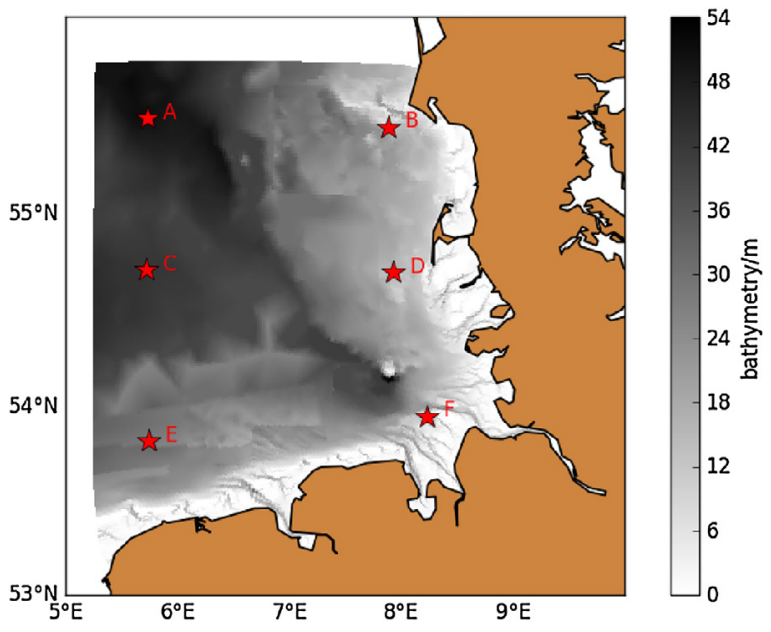

Fig. 1. Bathymetry of the German Bight. Red stars are six locations for wind drag coefficient analysis in Section 4. (For interpretation of the references to color in this figure legend, the reader is referred to the web version of this article.)
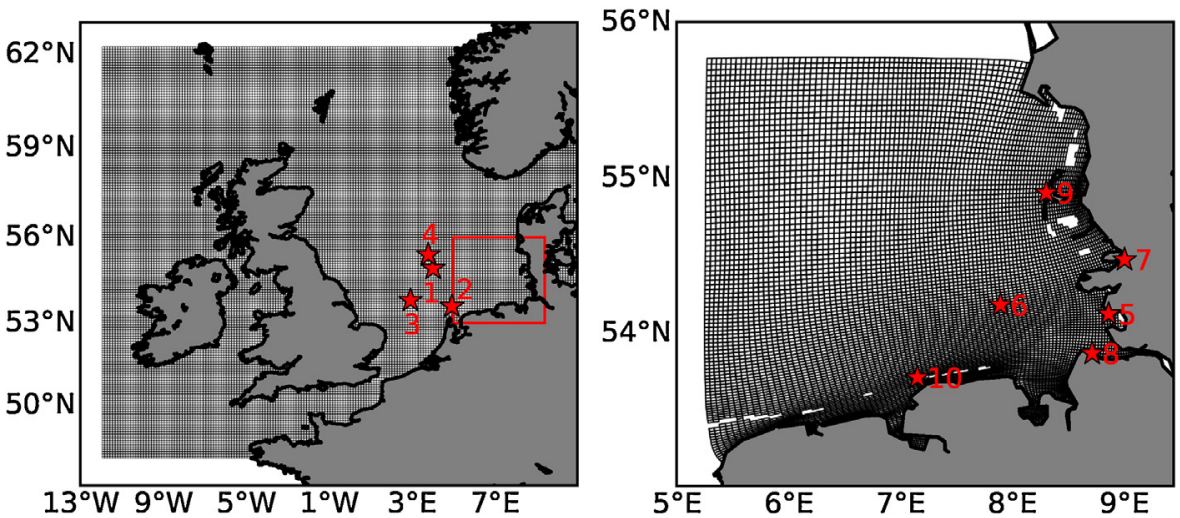

Fig. 2. Domain and grid of the model CSM (left) and GBM (right); the red stars represent locations of observation of water level, wave or wind: (1) F161, (2) 191, (3) J61, (4) A121, (5) Buesum, (6) Helgoland, (7) Husum, (8) Cuxhaven, (9) Sylt, (10) Norderney. (For interpretation of the references to color in this figure legend, the reader is referred to the web version of this article.)
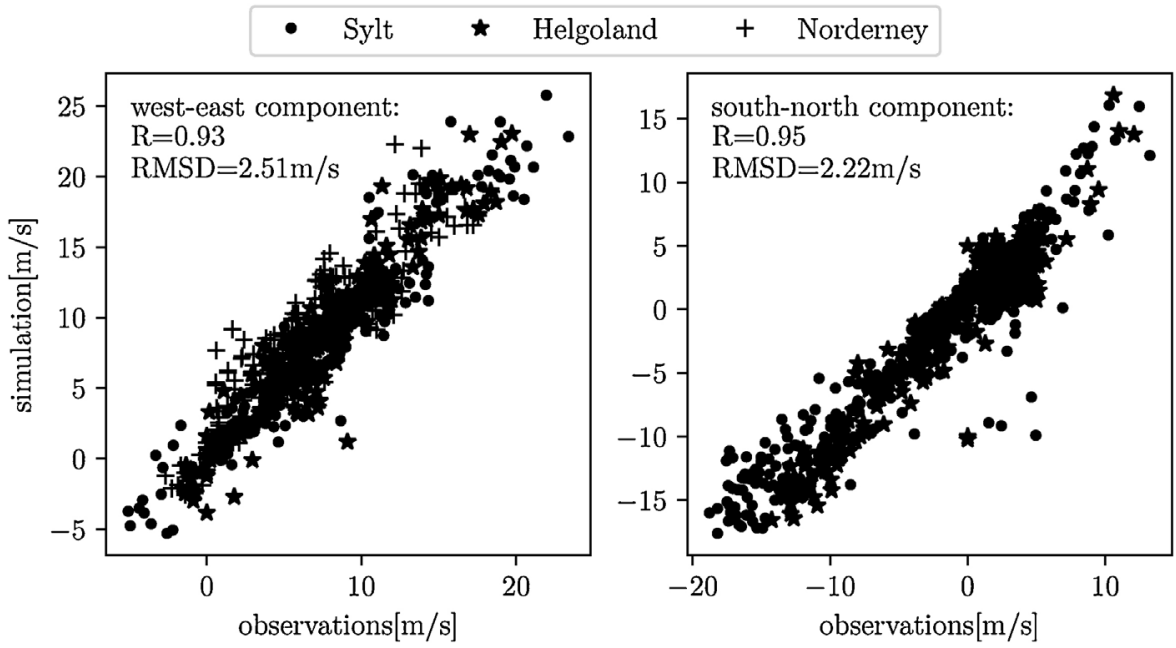

Fig. 3. Scatter plots of observed and simulated wind data at Sylt, Helgoland and Norderney. Left: for east component of wind; right: for north component of wind. 


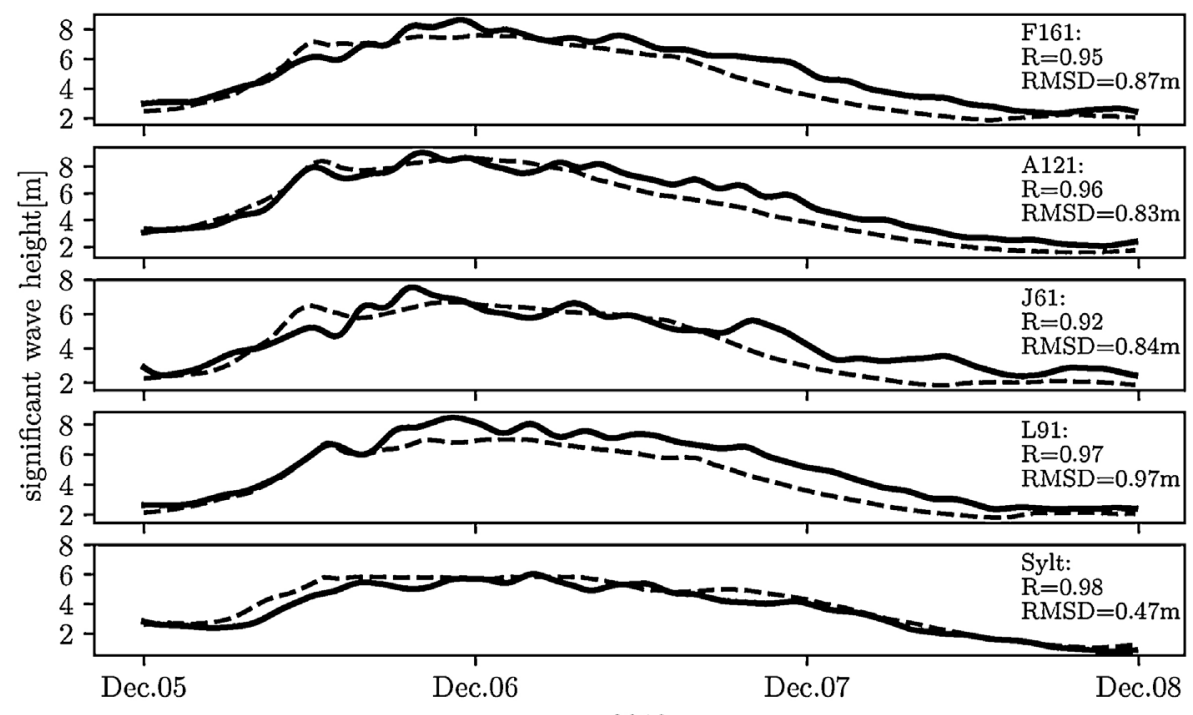

2013

Fig. 4. Comparison of modeled (dashed lines) and observed (solid lines) significant wave height at F161, A121, J61, L91 and Sylt.

south of Greenland on December 3rd 2013. It then moved to the east and swept across north Europe. The strong surge happened on December 5th and 6th, 2013 in the German Bight. The German North Sea coast experienced the second largest surge in the last 60 years during the 2-day storm passage.

The simulation period of the storm surge model is from December 2nd to 9th, 2013 and the time step is 1 min. The wave model covers the same period as the storm surge model. Before using the outputs of the wave model, they are validated using observations of significant wave height at five wave gauges (F161, A121, J61, L91 and Sylt) marked in Fig. 2. The storm Xaver produced huge wave in the North sea. The maximum significant wave height recorded by those wave gauges is $9.1 \mathrm{~m}$. The wave model well reproduces the maximum wave height for each wave gauges and captures how the wave height change with time as shown in Fig. 4. The figure also shows the correlation coefficient and RMSDs between observed and simulated wave height. The five correlation coefficients are very high (0.92-0.98) and the RMSDs and relatively small in view of such strong storm. Therefore, it is found that the wave model agrees well with observations in the study area and its results can be used for the following analysis.

\subsection{Water level data}

Water level data (meter) measured by tidal gauges at Helogland, Buesum, Cuxhaven and Husum (see Fig. 2) are used in this study for model validation and data assimilation. The time interval of the data is $10 \mathrm{~min}$ at each station.

\subsection{Adjoint-free 4Dvar}

Data assimilation is a mathematical method which combines numerical models and observations to improve the model skill (Lahoz et al., 2010). Models can be represented in a general form shown as below,

$$
x_{i+1}=M_{i}\left(x_{i}, p\right)
$$

where $M_{i}$ is the model operator at time $t_{i}$, which integrates the model state $x$ from $t_{i}$ to $t_{i+1}$ given the model parameter $p$. Model skill is denoted as a scalar cost function $J$ :

$$
\begin{gathered}
J\left(p, x_{i}\right)=\left(p-p_{b}\right)^{T} B^{-1}\left(p-p_{b}\right)+ \\
\sum_{i=1}^{N}\left(y_{i}-\mathrm{Hx}_{i}\right)^{T} R_{i}^{-1}\left(y_{i}-\mathrm{Hx}_{i}\right)
\end{gathered}
$$

where $p_{b}$ denotes the background value or first guess of $p, y_{i}$ is the observation vector of $x_{i}$ and $H$ is the observation operator. The superscript $T$ means vector transposing. The improvement of the model skill is achieved by adjusting $p$ and $x_{i}$ and minimizing the cost function $J$. Model state $x_{i}$ is determined by model parameter $p$ in Eq. (2), therefore $p$ is called control variable of the cost function $J$.

Basically, there are two ways of implementing data assimilation in numerical models (Evensen, 2009), i.e., sequential method and 4 Dvar. For sequential methods, such as 3Dvar and Kalman filter, the minimization of the cost function (Eq. (3)) takes place at one time step. While in the method of 4Dvar, observations over a given period are assimilated to minimize $J$. 4Dvar is preferred over sequential methods if there are very frequent observations because the too often data assimilation may destroy the smoothness of the model results. The advantage of 4Dvar over 3Dvar is that 4Dvar takes models into account and the cost function has a time component so that the model will dynamically consistent over the assimilation window. In addition, 4Dvar can perform any model 
parameter estimation other than model state. Thereby, 4Dvar is used in this study for the estimate of wind drag coefficient $C_{d}$.

The optimization method such as conjugate gradient is often used to reach the minimum of $J$ step by step. In the course of minimization, the gradient of $J$ with respect to the control variable $p$ must be known. The usual way to obtain the gradient in 4Dvar is adjoint method. But the development and maintenance of adjoint equations is very tough, making the implementation of 4Dvar difficult.

Zheng et al. (2016) proposed an adjoint-free 4Dvar. Twin experiments shows that this method improves model parameters effectively. It does not need the adjoint equations of the primitive model and can be implemented much easier than the adjoint method. The key step of the adjoint-free 4Dvar is running a model ensemble, and then the tangent linear equations of the primitive model can be obtained explicitly instead of its numerical form. For detailed derivation and validation of the method, readers are referred to Zheng et al. (2016).

The time window of the data assimilation is between 2013-12-05 12:00 and 2013-12-06 12:00. Over this period the storm had largest influence on the German Bight. The model parameters to be adjusted by data assimilation are $a$ and $b$ in Eq. (1). The first guess values of $a$ and $b$ are proposed by Smith (1980). $a=0.61, b=0.063$. Water level data at station Helgoland and Buesum are used for data assimilation, and water level data at Husum and Cuxhaven for validation.

\subsection{Influence of wave on wind drag coefficient $C_{d}$}

Wind stress $\tau$ is parametrized as the multiplication of air density $\rho_{a}$, wind drag coefficient $C_{d}$ and the square of wind speed $U_{z} z$ meters above the sea surface, that is,

$$
\tau=\rho_{a} C_{d}\left|U_{z}\right| U_{z}
$$

Many observations have proved that the logarithmic assumption is a reasonable representative of wind profile over the sea surface (Csanady and Gibson, 2002), that is

$$
U_{z} / u_{*}=(1 / \kappa) \ln \left(z / z_{0}\right)
$$

where $U_{z}$ is the wind speed $z$ meters above the sea surface, $u_{*}$ is shear velocity, $\kappa$ is Von Karman's constant and $z_{0}$ is roughness length of the sea surface. $u_{*}$ is defined as $u_{*}=\sqrt{\tau / \rho_{a}}$. Substituting Eq. (4) into (5), the relation between $C_{d}$ and $z_{0}$ is obtained,

$$
\sqrt{C_{d}}=\frac{\kappa}{\ln z / z_{0}}
$$

That means, once roughness length $z_{0}$ is known, $C_{d}$ can be determined uniquely by $z_{0}$.

As shown in Section 1, $C_{d}$ is often calculated given a linear function and wind speed. Another way to calculate $C_{d}$ is obtaining $z_{0}$ first and then Eq. (6) is used to calculate $C_{d}$. Wind speed, wave state or even atmospheric conditions are taken into account to parametrize $z_{0}$. In this paper, a formula proposed by Donelan et al. (1993) is used to obtain $z_{0}$ as shown below,

$$
z_{0} / \sigma=6.7 \times 10^{-4}\left(U_{10} / C_{p}\right)^{2.6}
$$

where $\sigma$ is root mean square wave height and $C_{p}$ is the wave phase speed at the peak frequency. $\sigma$ and $C_{p}$ are obtained from the output of the wave model. Wind speed $U_{10}$ is from DWD regional model. Donelan's method is regarded to be a better parameterization scheme than linear functions. It was derived from observational wind stress and wave data in North Sea off the coast of the Netherlands, which is close to our study area. Donelan's method has already been applied in many recent wave-wind coupling models (Sun et al., 2013; Bertin et al., 2015; Mao and Xia, 2016).

\section{Results}

Fig. 5 shows the time series of water level from models and observations over the time window of data assimilation. Before data assimilation, the problem of the model is that the water level is under estimated during the strong storm. It can be seen that data assimilation improves the model skill significantly. Modeled water level at the four stations becomes much closer to observations than that before data assimilation.

Table 1 shows the RMSDs of water level before and after data assimilation at the four stations. The RMSDs at Buesum and Helgoland are decreased as expected because they are used in the data assimilation. RMSDs at Cuxhaven and Husum are also reduced significantly, indicating that data assimilation is effective to improve the model skill over a large domain. The relative decrease of RMSD is more than $60 \%$ at Buesum, Husum and Cuxhaven. At Helgoland, the relative decrease is smaller than that at other three stations. This is because Helgoland is off the land with larger depth and the variation of water level is smaller than coastal stations. Table 1 also shows the correlation coefficients between modeled and observed water level. At all the four station, the correlation coefficients are improved from around 0.950 to more than 0.970 , indicating the effectiveness of data assimilation.

In order to know whether data assimilation is able to reduce the error caused by uncertainties of wind drag coefficient $C_{d}$, another experiment was designed. Water level is modeled over the period between December 2nd and 4th 2013. During this period the wind is weak over the German Bight, therefore, it represents a normal weather condition. Fig. 6 shows the energy caused by water level variation. The potential energy of a water column per unit horizontal area $E$ in a given period between $t_{1}$ and $t_{2}$ is defined by 

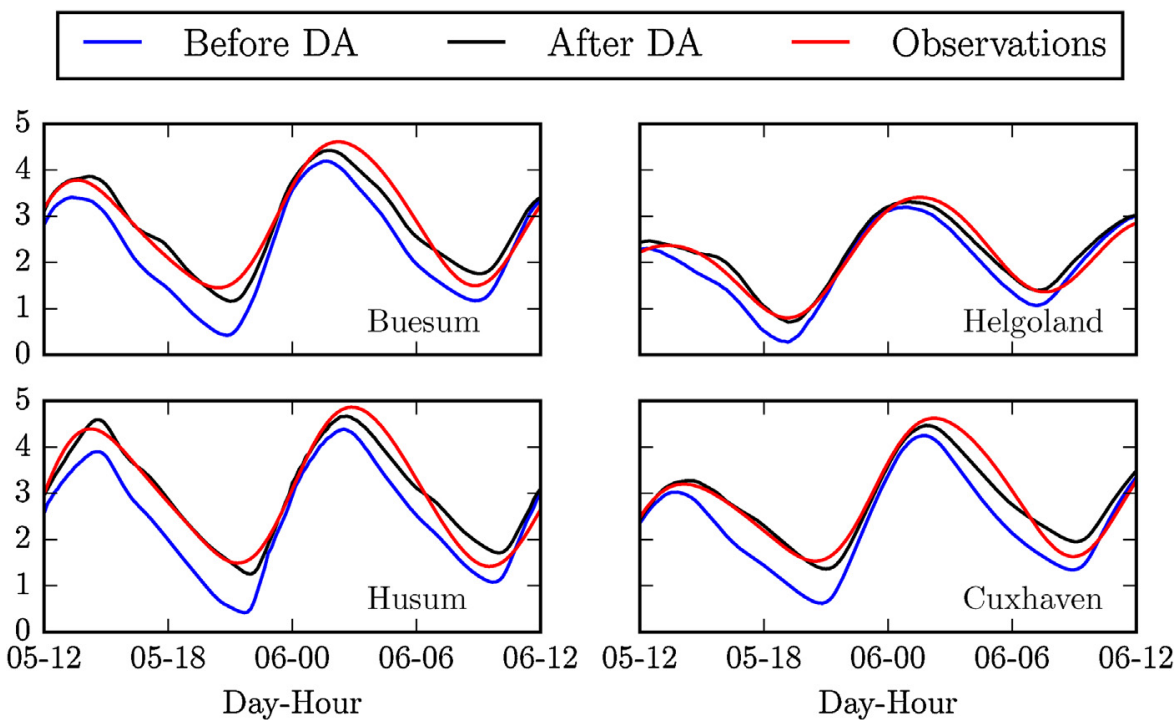

Fig. 5. Time series of water level before (blue) and after (black) data assimilation and the observations (red) in the time window from 2013-12-05 12:00UTC to 2013-12-06 12:00UTC at four tidal gauges. (For interpretation of the references to color in this figure legend, the reader is referred to the web version of this article.)

Table 1

RMSD and correlation coefficient of water level $(\mathrm{m})$ between model and observations before and after data assimilation.

\begin{tabular}{llllll}
\hline & \multicolumn{2}{l}{ RMSD } & Relative RMSD & \multicolumn{2}{c}{ Correlation Coefficient } \\
\cline { 2 - 4 } & Before & After & & Before \\
\hline Buesum & 0.554 & 0.213 & $61.5 \%$ & 0.956 & 0.969 \\
Helgoland & 0.283 & 0.129 & $54.4 \%$ & 0.955 & 0.978 \\
Husum & 0.589 & 0.186 & $68.4 \%$ & 0.956 & 0.980 \\
Cuxhaven & 0.526 & 0.197 & $62.5 \%$ & 0.971 \\
\hline
\end{tabular}

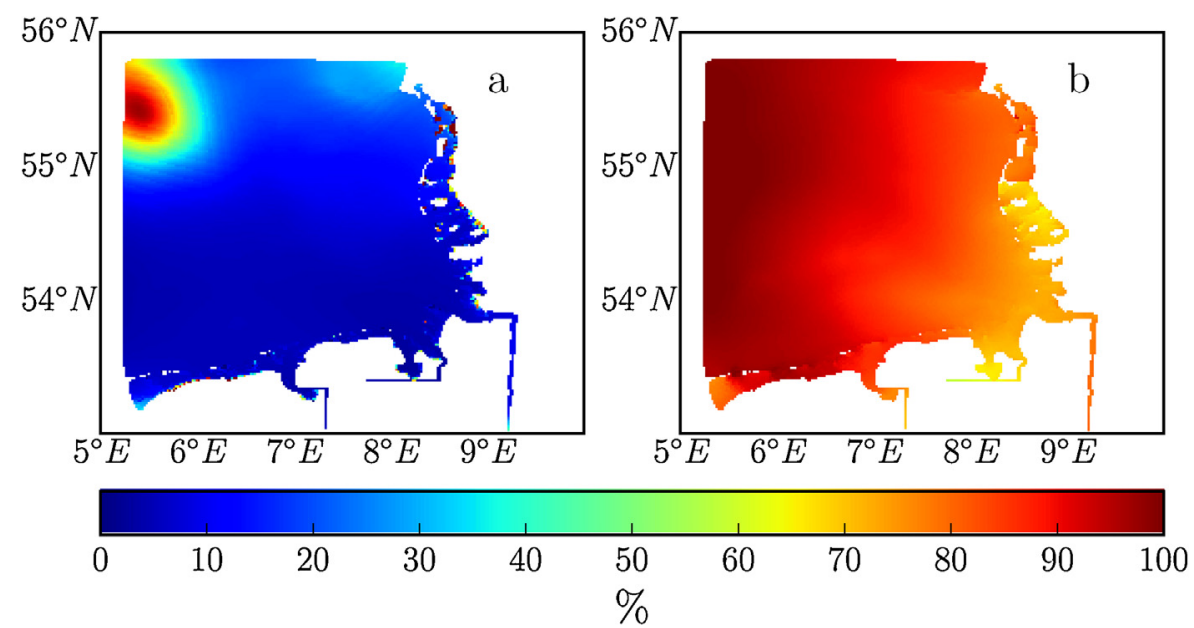

Fig. 6. Ratio of wind induced energy relative to total energy. Left: under normal weather condition; right: during the storm Xaver.

$$
E=\frac{1}{2} \int_{t_{1}}^{t_{2}} \rho_{w} g \zeta^{2} \mathrm{dt}
$$

Here $\rho_{w}=1025 \mathrm{~kg} \mathrm{~m}^{-3}$ is the sea water density, $g$ is gravitational acceleration and $\zeta$ is the water level relative to the mean water level. Total energy $E_{t}$ is calculated with the total water level including the effect of wind and tide, while the surge energy $E_{s}$ is calculated only with the surge (no tide). A percentage ratio $\alpha=100 \frac{E_{s}}{E_{t}}$ is used to indicate the relative importance of wind effect for total water level. 


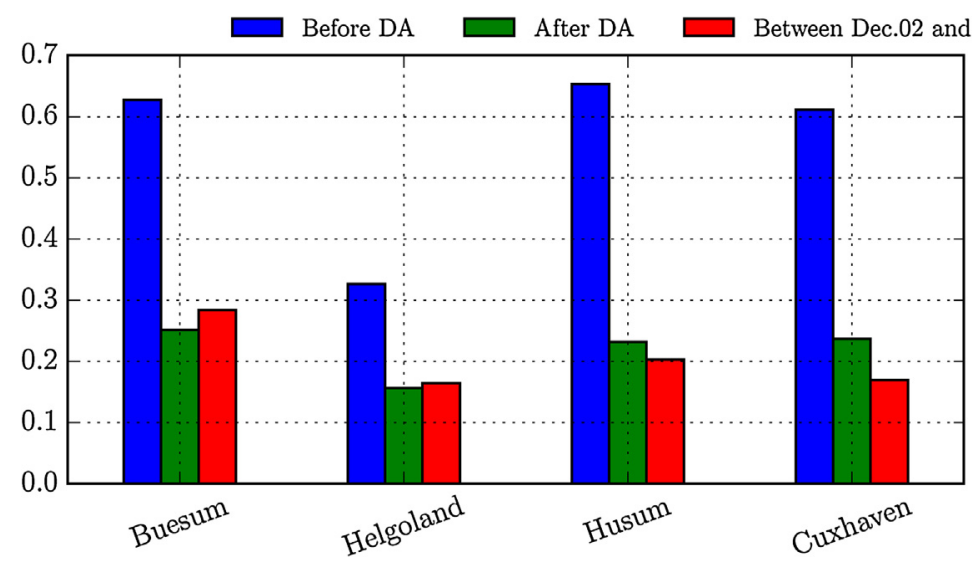

Fig. 7. RMSD of water level (blue: before data assimilation; green: after data assimilation; red: under normal weather conditions). (For interpretation of the references to color in this figure legend, the reader is referred to the web version of this article.)

Fig. 6 shows that the variation of water level is mainly produced by tide in the period between December 2 nd and 4 th. It is seen that the effect of wind can be neglected under normal weather conditions. While during the storm Xaver, both tide and wind stress play important roles in the water level variation. The model errors are approximately the summation of model errors under normal weather conditions and errors caused by uncertainties of wind stress. The bars in Fig. 7 represent the RMSDs of water level at the four tidal stations. The blue bars are the RMSDs before data assimilation and the green bars after data assimilation. The red bars are RMSDs between December 2nd and 4th, representing the averaged RMSD under normal weather conditions. The green bars are shorter than the blue bars, meaning that the errors are reduced by data assimilation. The height of the green bars are almost the same as the red bars, indicating that the errors caused by wind stress have been removed by data assimilation.

\section{Discussions}

Since the model skill is improved significantly by adjusting wind drag coefficient $C_{d}$ (Table 2), it is natural to ask whether data assimilation adjusted $C_{d}$ is reasonable in the physical sense or it is just a tuning parameter, which makes the model improved only mathematically. The way to answer this question is to compare $C_{d}$ adjusted by data assimilation with $C_{d}$ calculated with other methods. These methods include wind-wave coupling models, direct observations of strong wind and the wave related formula proposed by Donelan et al. (1993) (Eq. (7)) mentioned in Section 2.4.

The wind speed range over the domain of the German Bight during the time window of data assimilation is 16.7-33.7 m/s. According to the study of Powell et al. (2003), $C_{d}$ increases with the increase of wind speed up to about $33 \mathrm{~m} / \mathrm{s}$ and then decreases. This critical wind speed is disputable. Jarosz et al. (2007) calculated $C_{d}$ using observational data of current and they found that the critical wind speed is $32 \mathrm{~m} / \mathrm{s}$. In Holthuijsen et al. (2012)'s study, the critical wind speed is $40 \mathrm{~m} / \mathrm{s}$. Therefore, during the storm Xaver the assumption that $C_{d}$ increases monotonously with wind speed in the range of $16.7-33.7 \mathrm{~m} / \mathrm{s}$ is acceptable. Actually, the valid range of Smith formula is $6-22 \mathrm{~m} / \mathrm{s}$ because Smith did not capture very strong wind speed. As mentioned by many researchers, $C_{d}$ is not only influenced by wind speed, but also by air stability, wave state in a complex way. A linear relation is not enough to express the variations of $C_{d}$ over a long range of wind speed. Therefore, The uncertainty of this formula may increase during strong storms such as Xaver.

Strong storms are rare, and what's more, during a strong storm, it is very difficult to obtain reliable observational data. Therefore, It is not easy to find much literature on the relation between $C_{d}$ and wind speed under high wind conditions. In this part, $C_{d}$ during hurricanes or typhoons measured by three researchers are compared to $C_{d}$ adjusted by data assimilation. Fig. 8 shows those $C_{d} s$ (solid lines) at wind speed from 15 to $35 \mathrm{~m} / \mathrm{s}$. Moon et al. (2004) investigated the effect of wave on air-sea momentum exchange with the wave model WAVE-WATCH III. They found that in the wind speed range between 10 and $45 \mathrm{~m} / \mathrm{s}, C_{d}$ increases with the increase of wind speed. Zhao et al. (2015) studied wind drag coefficient based on wind measurement from a coastal meteorological tower in South China Sea. They found that $C_{d}$ increases with wind speed until $24 \mathrm{~m} / \mathrm{s}$, which is about $5-15 \mathrm{~m} / \mathrm{s}$ smaller than previous findings. Hsu et al. (2017) estimated wind stress during a strong typhoon Megi in South China Sea using observations of current velocity and a linear momentum budget model. They found that the value of $C_{d}$ reaches maximum value $3.5 \times 10^{-3}$ when $33 \mathrm{~m} / \mathrm{s}$ (critical wind

Table 2

$a$ and $b$ in Eq. (1) before and after data assimilation.

\begin{tabular}{lll}
\hline & $a$ & $b$ \\
\hline Before DA & 0.61 & 0.063 \\
After DA & 0.706 & 0.108 \\
\hline
\end{tabular}




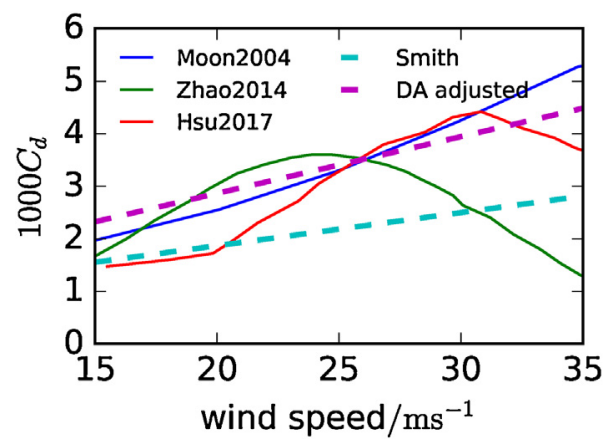

Fig. 8. Relations between $C_{d}$ and wind speed from literature and this study.

speed). $C_{d}$ decreases with the increase of wind speed after that. $C_{d}$ is $2.6 \times 10^{-3}$ when the wind speed is $37 \mathrm{~m} / \mathrm{s}$. Due to the different study areas and methods, relation between $C_{d}$ and wind speed from the three mentioned-above literature shows obvious deviations. But at the wind speed larger than $20 \mathrm{~m} / \mathrm{s}, C_{d}$ adjusted by data assimilation is much closer to those in the literature than Smith formula, indicating that data assimilation adjusts $C_{d}$ in a reasonable way under stormy weather conditions.

Fig. 9 shows the time series comparison of $C_{d}$ at six locations in the German Bight model domain. The six locations are shown in Fig. 1 and they represent locations ranging from deep water to shallow water (A, C, E are in deep water and the other three are closer to coastlines). Wind drag coefficient $C_{d}$ is also calculated according to the Donelan's method in Eq. (7) using the wave model output and wind speed data from DWD. For brevity, $C_{d 1}$ represents the wind drag coefficient calculated from Smith formula which is the first guess of data assimilation, $C_{d 2}$ represents the wind drag coefficient calculated from the linear formula adjusted by data assimilation, and $C_{d 3}$ represents the wind drag coefficient calculated from the Donelan method. It can be found that $C_{d 2}$ and $C_{d 3}$ are very close at location $\mathrm{A}, \mathrm{C}$ and E, much larger than $C_{d 1}$. While at location B, D and F, $C_{d 2}$ and $C_{d 3}$ have much larger deviations and $C_{d 2}$ is smaller. In deep water areas, data assimilation not only optimizes the storm surge simulation but also adjusts the linear function in a way very similar to how $C_{d}$ changes with both wave and wind speed. Therefore, in deep water, the linear function adjusted by data assimilation is consistent with the wave-related variation of $C_{d}$. On the other hand, why in the shallow water, the deviation is still very significant?

To investigate this question, scatter diagrams between wind speed and $C_{d 3}$ are plotted as shown in Fig. 10D-F. The scatter of $C_{d 3}$ is extracted from three different domains shown in the upper three figures in Fig. 10. Domain 1 is indicated in the blue patch in Fig. 10A, representing the deep water area, and the average water depth over domain 1 is 38.9 m. Domain 2 are shown in Fig. $10 \mathrm{~B}$, containing more shallow water area than the domain 1, and the average depth of domain 2 excluding domain 1 is $14.4 \mathrm{~m}$. Domain 3 includes all water cells in the model domain as shown in Fig. 10C, and the average depth without domain 1 and 2 is $5.5 \mathrm{~m}$.
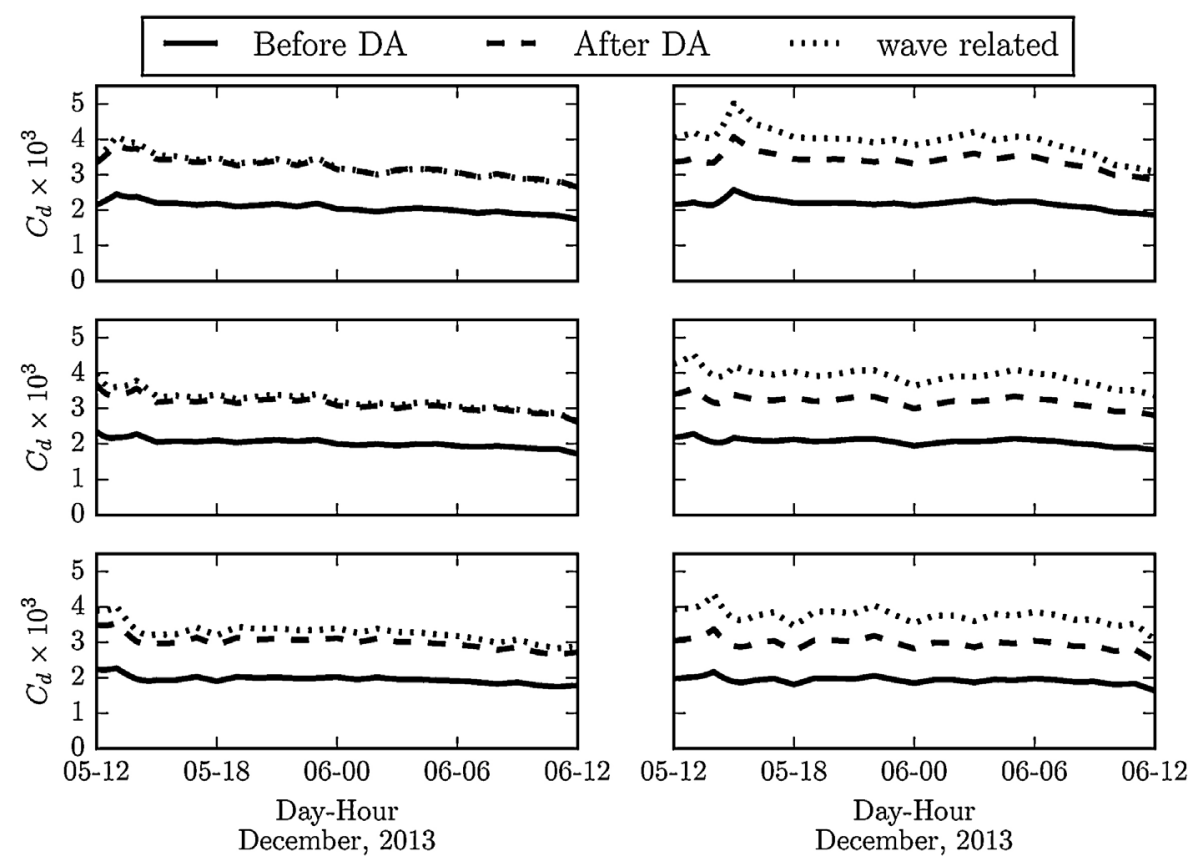

Fig. 9. Comparison of $C_{d}$ over the time window of data assimilation at six locations. Solid line: before data assimilation; dashed line: after data assimilation; dotted line: Donelan method. 


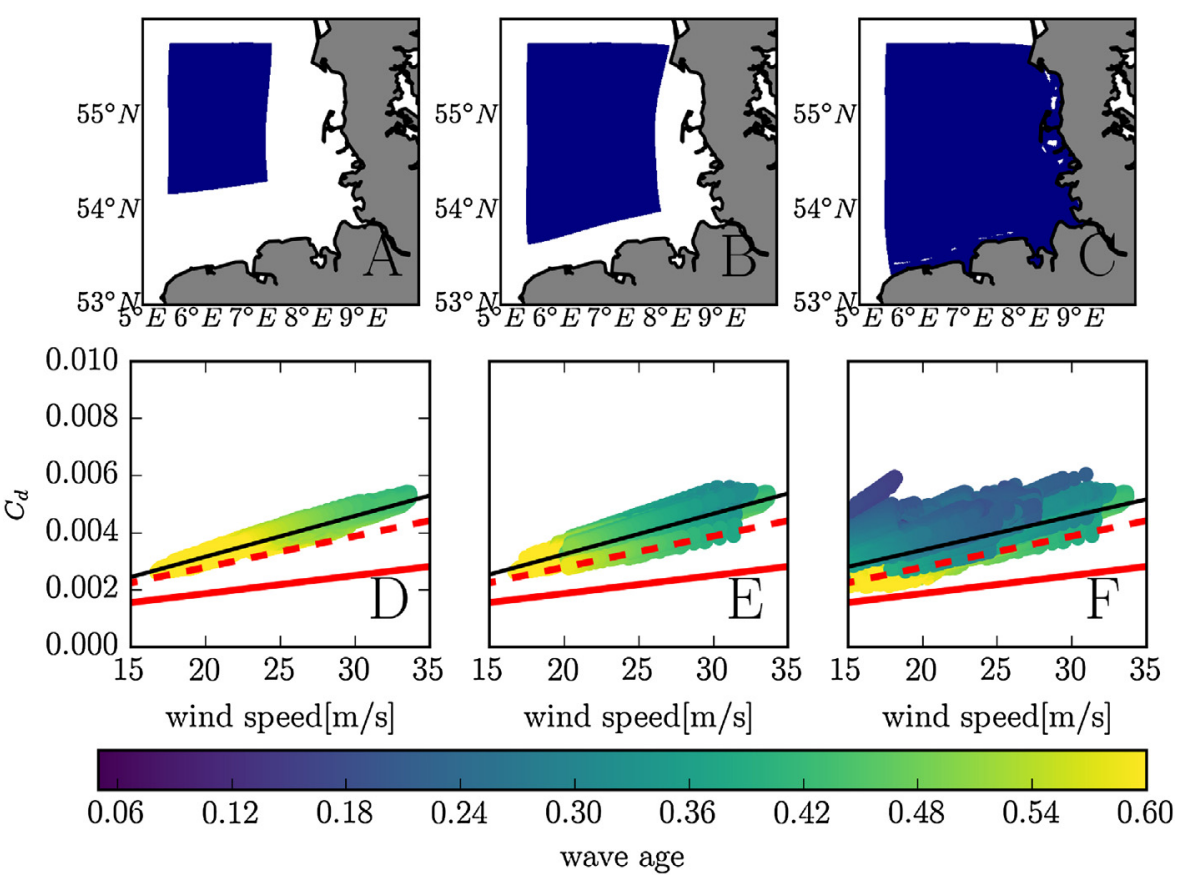

Fig. 10. Scatter diagrams of $C_{d}$ calculated using Donelan method over different domains indicated in blue patch in A, B and C. (For interpretation of the references to color in this figure legend, the reader is referred to the web version of this article.)

Linear regression is performed on the scatter in the three domains. The derived linear functions are shown in Table 3. In Fig. 10D, the scatter is $C_{d 3}$ over domain 1 during the time window of data assimilation. It can be seen from Fig. 10D that the function derived from linear regression (black solid line) is quite similar to the linear function adjusted by data assimilation (red dashed line) in the wind speed range from 20 to $30 \mathrm{~m} / \mathrm{s}$, indicating improvement of $C_{d}$ compared with Smith formula (red solid line). Scatter in Fig. $10 \mathrm{E}$ covers more shallow water areas than that in Fig. 10D. The regression-derived linear function is still similar to that adjusted by data assimilation, but the variance of the data are larger and the value of $R^{2}$ is smaller as shown in Table 3 . When $C_{d 3}$ over all shallow water are included in the scatter diagram as shown in Fig. $10 \mathrm{~F}$, the relation between $C_{d 3}$ and wind speed becomes very scattered. For a given wind speed, $C_{d}$ has a larger variation and the linear relation between them is no longer valid. This is why in the shallow water, the deviations between $C_{d 2}$ and $C_{d 3}$ become very large as shown in Fig. 9.

The colors of the scatter in Fig. $10 \mathrm{D}-\mathrm{F}$ indicate wave age. Wave age is defined as $C_{p} / U_{10}$, which measures the development stage of wave state relative to wind(Edson et al., 1999). According to the study of Sjöblom and Smedman (2002), wave with wave age more than 0.5 is classified as mature wave. Yellow means mature wave and blue means young wave in the color bar in Fig. 10. Smith (1980) found the wave age has less relation to wind drag coefficient than wind speed, but many other researchers found wave age is also a very important factor when the wave is still not mature (Gao et al., 2009). In deep water as shown in Fig. 10D, most waves during the time window of data assimilation are old. As shown in Fig. 11, when the wave enters into shallow water, the wave length becomes shorter and wave phase speed becomes smaller, making the wave age smaller and the sea surface rougher. As a result, wind drag coefficient $C_{d}$ with the same wind speed is larger in shallow water than in deep water, which is consistent with Chen and Curcic (2016)'s conclusions in the study of atmosphere-wave-ocean model prediction of hurricane-induced ocean surface waves near landfall. They found that wind drag coefficient in shallow water $(<20 \mathrm{~m})$ is $4 \%$ larger in high wind speed and up to $25 \%$ in low wind speed than that in deeper water.

\section{Conclusions}

In this paper, a data assimilation method, adjoint free 4Dvar, is used to improve the storm surge simulation in the German Bight. Adjoint free 4Dvar is effective for parameter estimation and easy to be implemented into ocean models. By adjusting the linear

Table 3

Linear regression of the scatter between $C_{d}$ and wind speed.

\begin{tabular}{llll}
\hline & Slope & Intercept & $R^{2}$ \\
\hline 1 & $1.42 \times 10^{-4}$ & $3.04 \times 10^{-4}$ & 0.879 \\
2 & $1.42 \times 10^{-4}$ & $4.03 \times 10^{-4}$ & 0.796 \\
3 & $1.18 \times 10^{-4}$ & $1.03 \times 10^{-3}$ & 0.583 \\
\end{tabular}




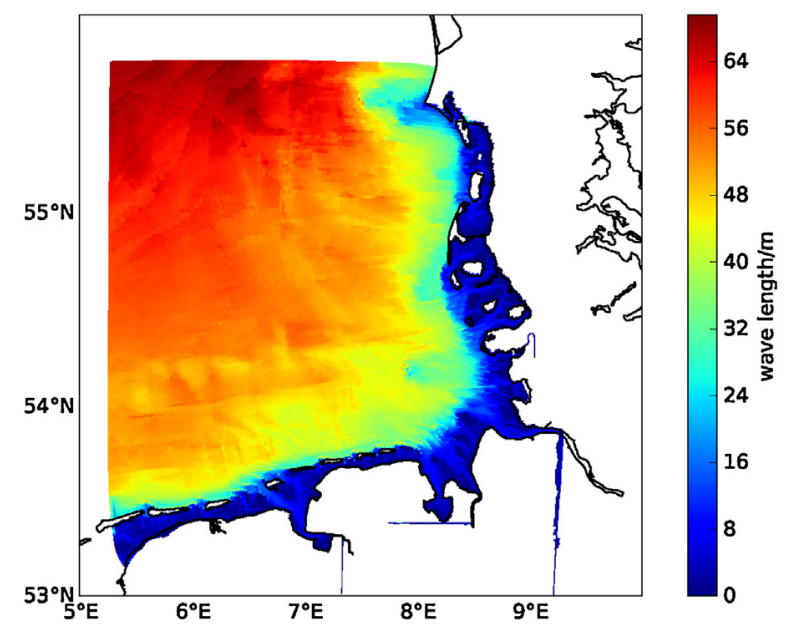

Fig. 11. Wave length (m) over the German Bight at 2013-12-06 00:00.

function of wind drag coefficient with respect to wind speed, the modeled water level is improved significantly with comparison to observations. The improvements are not only at the stations for data assimilation, but also at the stations for validation, indicating that data assimilation is able to improve the model over a large domain. Data assimilation can reduce most of model errors due to the uncertainties of the wind drag coefficient parameterization.

Wind drag coefficient is not only changing with wind speed, but also with many other parameters. Among them, wave state plays an important role. Comparison between $C_{d}$ calculated from Donelan method and from linear function is performed. In deep water, $C_{d}$ adjusted by data assimilation is very similar to the wave-related $C_{d}$. While in shallow water, the former $C_{d}$ is still much smaller than the wave-related $C_{d}$. The scatter plots of wave-related $C_{d}$ indicate that in deep water, $C_{d}$ and wind speed have a good approximate linear relation. As water becomes shallower, the shoaling effect makes the wave length smaller, increasing the roughness of the sea surface. Thus, in shallow water, $C_{d}$ tends to be larger than that in deep water and has a larger variance if the linear function with respect to wind speed is adopted. In most areas of the German Bight, the linear function of $C_{d}$ adjusted by data assimilation is consistent with wave-related $C_{d}$. Therefore, the linear relation between $C_{d}$ and wind speed is a practical parameterization scheme for storm surge simulation. Data assimilation is able to adjust the linear function in a physically reasonable way.

Wave state is influenced by wind speed, wind direction, water depth and coastline orientations. Therefore, the development of a wave is not only dependent on wind but also on locations. Due to the close relation between wind drag coefficient and wave state, the linear function of wind drag relative to wind speed is not fixed but a local variable. That means linear function of wind drag derived from observations at one locations may not apply to other areas. Although in this paper, data assimilation practically improves the storm surge model skill, the linear function of wind drag coefficient is independent of locations. If observational data covering large areas is used for data assimilation, the improvement of storm surge model skill will be not as significant as in this paper due to the large spatial variation of linear wind drag coefficient function. Such problems can be relieved by using wave-related process should be taken into account, which is better in the physical sense. Wave-related parameterization schemes like Donelan's method also have uncertainties to some extent, and it can also be improved by adjoint-free 4Dvar used in this paper.

Although observational data of water level is usually of high accuracy, it still has errors from instruments, sampling frequency or inconsistent locations with locations of modeled water level. In this paper it is assumed that observational data of water level is perfect, and no weight is added on the control variables $a$ and $b$ in the cost function of 4Dvar. This would make the adjusted $a$ and $b$ overly adjusted to the direction of observational data. In the future study, the accuracy of observations and control variables will be investigated and applied in the data assimilation.

\section{References}

Amorocho, J., DeVries, J., 1980. A new evaluation of the wind stress coefficient over water surfaces. J. Geophys. Res.: Oceans 85 (C1), $433-442$.

Bertin, X., Li, K., Roland, A., Bidlot, J.R., 2015. The contribution of short-waves in storm surges: two case studies in the bay of biscay. Cont. Shelf Res. 96, 1-15. Broquet, G., Moore, A., Arango, H., Edwards, C., 2011. Corrections to ocean surface forcing in the California current system using 4D variational data assimilation. Ocean Model. 36 (1), 116-132.

Chen, S.S., Curcic, M., 2016. Ocean surface waves in hurricane Ike (2008) and superstorm sandy (2012): coupled model predictions and observations. Ocean Model. 103 (5), 161-176.

COSMO, 2007. Operations at dwd. Tech. rep. cosmo-eu.

Csanady, G.T., Gibson, M., 2002. Air-sea interaction: laws and mechanisms. Appl. Mech. Rev. 55 (6), 117.

Dietrich, J.C., Muhammad, A., Curcic, M., Fathi, A., Dawson, C.N., Chen, S.S., Luettich, R.A.J., 2018. Sensitivity of storm surge predictions to atmospheric forcing during hurricane Isaac. J. Waterway Port Coast. Ocean Eng. 144 (1), 04017035.

Donelan, M.A., Dobson, F.W., Smith, S.D., Anderson, R.J., 1993. On the dependence of sea surface roughness on wave development. J. Phys. Oceanogr. 23 (9), $2143-2149$.

Edson, J., Paluszkiewicz, T., Sandgathe, S., Vincent, L., Goodman, C.T.L., Hollister, J., Colton, M., 1999. Coupled Marine Boundary Layers and Air-Sea Interaction Initiative: Combining Process Studies, Simulations, and Numerical Models. 
Egbert, G.D., Erofeeva, S.Y., 2002. Efficient inverse modeling of barotropic ocean tides. J. Atmos. Ocean. Technol. 19 (2), $183-204$.

Evensen, G., 2009. Data Assimilation: The Ensemble Kalman Filter. Springer Science \& Business Media.

Feng, X., Olabarrieta, M., Valle-Levinson, A., 2016. Storm-induced semidiurnal perturbations to surges on the US eastern seaboard. Cont. Shelf Res. 114, 54-71.

Gao, Z., Wang, Q., Zhou, M., 2009. Wave-dependence of friction velocity, roughness length, and drag coefficient over coastal and open water surfaces by using three databases. Adv. Atmos. Sci. 26 (5), 887-894.

Geernaert, G., Larsen, S., Hansen, F., 1987. Measurements of the wind stress, heat flux, and turbulence intensity during storm conditions over the north sea. J. Geophys. Res.: Oceans 92 (C12), 13127-13139.

Holthuijsen, L.H., Powell, M.D., Pietrzak, J.D., 2012. Wind and waves in extreme hurricanes. J. Geophys. Res. Oceans 117 (C9), $45-57$.

Hsu, J.-Y., Lien, R.-C., D’Asaro, E.A., Sanford, T.B., 2017. Estimates of surface wind stress and drag coefficients in typhoon megi. J. Phys. Oceanogr. 47 (3), 545-565. Hydraulics, D., 2007. User Manual delft3d-flow. WL Delft Hydraulics.

Hydraulics, W.D., 2002. Delft3d-wave User Manual Version 2.01. WL IDelft Hydraulics, Delft, The Netherlands.

Jarosz, E., Mitchell, D.A., Wang, D.W., Teague, W.J., 2007. Bottom-up determination of air-sea momentum exchange under a major tropical cyclone. Science 315 (5819), 1707-1709.

Jiao, J., 2014. Morphodynamics of Ameland Inlet: Medium-term delft3d Modelling. Delft University of Technology, TU Delft (Ph.D. thesis).

Krien, Y., Testut, L., Islam, A.K.M.S., Bertin, X., Durand, F., Mayet, C., Tazkia, A.R., Becker, M., Calmant, S., Papa, F., 2017. Towards improved storm surge models in the northern Bay of Bengal. Cont. Shelf Res. 135, 58-73.

Kuang, C., Lee, J.H.W., Harrison, P.J., Yin, K., 2016. Effect of wind speed and direction on summer tidal circulation and vertical mixing in Hong Kong waters. J. Coast. Res. 27 (6), 74-86.

Lahoz, W., Khattatov, B., Menard, R., 2010. Data Assimilation: Making Sense of Observations. Springer Science \& Business Media.

Large, W., Pond, S., 1981. Open ocean momentum flux measurements in moderate to strong winds. J. Phys. Oceanogr. 11 (3), 324-336.

Li, Y., Peng, S., Yan, J., Xie, L., 2013. On improving storm surge forecasting using an adjoint optimal technique. Ocean Model. 72 (12), 185-197.

Mao, M., Xia, M., 2016. Dynamics of wave-current-surge interactions in lake Michigan: a model comparison. Ocean Model.

Moon, I.J., Hara, T., Ginis, I., Belcher, S.E., Tolman, H.L., 2004. Effect of surface waves on air sea momentum exchange. Part I: Effect of mature and growing seas. J. Atmos. Sci. 61 (19), 2321-2333.

Peng, S., Li, Y., Xie, L., 2013. Adjusting the wind stress drag coefficient in storm surge forecasting using an adjoint technique. J. Atmos. Ocean. Technol. 30 (3), 590-608.

Powell, M.D., Vickery, P.J., Reinhold, T.A., 2003. Reduced drag coefficient for high wind speeds in tropical cyclones. Nature 422 (6929), 279-283.

Sjöblom, A., Smedman, A.-S., 2002. The turbulent kinetic energy budget in the marine atmospheric surface layer. J. Geophys. Res.: Oceans 107 (C10).

Smith, S., Banke, E., 1975. Variation of the sea surface drag coefficient with wind speed. Q. J. R. Meteorol. Soc. 101 (429), 665-673.

Smith, S.D., 1980. Wind stress and heat flux over the ocean in gale force winds. J. Phys. Oceanogr. 10 (5), $709-726$.

Sun, Y., Chen, C., Beardsley, R.C., Xu, Q., Qi, J., Lin, H., 2013. Impact of current-wave interaction on storm surge simulation: a case study for hurricane bob. J. Geophys. Res.-Space Phys. 118 (5), 2685-2701.

Wang, Y., Gao, T., Han, Z., Liu, Q., 2017a. Impacts of wind-field correction on the numerical simulation of storm-surge inundation during typhoon "rammasun". Estuar. Coast. Shelf Sci. 196.

Wang, Y., Zheng, X., Yu, X., Liu, X., 2017b. Temperature and salinity effects in modeling the trajectory of the 2011 penglai 19-3 oil spill. Mar. Georesour. Geotechnol. 35 (7), 946-953

Weaver, R.J., Slinn, D.N., 2015. Effect of wave forcing on storm surge. Coastal Engineering 2004 - International Conference 1532-1538.

Wu, J., 1969. Froude number scaling of wind-stress coefficients. J. Atmos. Sci. 26 (3), 408-413.

Yelland, M., Taylor, P.K., 1996. Wind stress measurements from the open ocean. J. Phys. Oceanogr. 26 (4), $541-558$.

Zhao, Z., Liu, C., Li, Q., Dai, G., Song, Q., Lv, W., 2015. Typhoon air-sea drag coefficient in coastal regions. J. Geophys. Res. Oceans 120 (2), 716-727.

Zheng, X., Mayerle, R., Xing, Q., Jaramillo, J.F., 2016. Adjoint free four-dimensional variational data assimilation for a storm surge model of the German North Sea. Ocean Dyn. 66 (8), 1-14. 